ARTICLE

\title{
Substrate regulation leads to differential responses of microbial ammonia-oxidizing communities to ocean warming
}

\author{
Zhen-Zhen Zheng' ${ }^{1}$ Li-Wei Zheng ${ }^{2}$, Min Nina Xu (1) 1,3, Ehui Tan (1) ${ }^{2}$, David A. Hutchins (1) ${ }^{3}$, Wenchao Deng ${ }^{1}$,

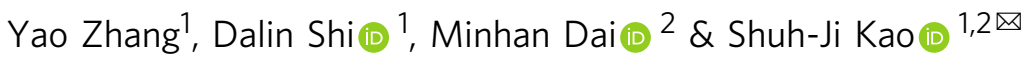

In the context of continuously increasing anthropogenic nitrogen inputs, knowledge of how ammonia oxidation $(\mathrm{AO})$ in the ocean responds to warming is crucial to predicting future changes in marine nitrogen biogeochemistry. Here, we show divergent thermal response patterns for marine $\mathrm{AO}$ across a wide onshore/offshore trophic gradient. We find ammonia oxidizer community and ambient substrate co-regulate optimum temperatures $\left(T_{\text {opt }}\right)$, generating distinct thermal response patterns with $\mathrm{T}_{\text {opt }}$ varying from $\leq 14{ }^{\circ} \mathrm{C}$ to $\geq 34^{\circ} \mathrm{C}$. Substrate addition elevates $T_{\text {opt }}$ when ambient substrate is unsaturated. The thermal sensitivity of kinetic parameters allows us to predict responses of both $A O$ rate and $T_{\text {opt }}$ at varying substrate and temperature below the critical temperature. A warming ocean promotes nearshore $\mathrm{AO}$, while suppressing offshore $\mathrm{AO}$. Our findings reconcile field inconsistencies of temperature effects on $\mathrm{AO}$, suggesting that predictive biogeochemical models need to include such differential warming mechanisms on this key nitrogen cycle process.

\footnotetext{
${ }^{1}$ State Key Laboratory of Marine Environmental Science, College of the Environment and Ecology, Xiamen University, Xiamen, Fujian, P. R. China. ${ }^{2}$ State Key Laboratory of Marine Environmental Science, College of Ocean and Earth Sciences, Xiamen University, Xiamen, Fujian, P. R. China. ${ }^{3}$ Marine and

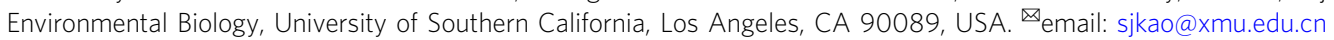


A mmonia oxidation (AO), the first step in nitrification, connects the most reduced and oxidized inorganic nitrogen species in the ocean. It therefore replenishes the marine pools of nitrite and provides oxidized substrates for denitrification and annamox, two primary nitrogen loss terms in the ocean ${ }^{1,2}$. Thus, AO plays a crucial role in the marine nitrogen cycle. In addition, AO interacts with the ocean carbon cycle from various perspectives, and is therefore involved in multiple climate feedback processes. For example, chemoautotrophic ammoniaoxidizing organisms fix inorganic carbon ${ }^{3}$, while the end product of nitrification provides approximately half of the nitrate consumed by growing phytoplankton on a global scale 4 . On the other hand, $\mathrm{AO}$ generates nitrous oxide $\left(\mathrm{N}_{2} \mathrm{O}\right)$ as a by-product ${ }^{5}$, a potent greenhouse gas with a $\sim 300$-fold higher greenhouse gas potential per molecule than carbon dioxide. Thus, AO helps to make the ocean a net source of $\mathrm{N}_{2} \mathrm{O}$ to the atmosphere. In view of global change and the rapid increases in the influx of anthropogenic nitrogen into the marine environment ${ }^{6,7}$, factors like acidification ${ }^{8,9}$, stratification, deoxygenation, and especially warming that may affect the ammonia oxidation rate (AOR) and AO microbial community structure, need to be addressed ${ }^{10,11}$. Only then can these environmental change factors be properly incorporated into nitrogen-driven biogeochemical models to make accurate climate predictions.

Temperature is recognized as a primary global driver to tune biological metabolic rates ${ }^{12}$. However, knowledge of how marine $\mathrm{AO}$ responds to warming remains underexplored, especially for areas having high AOR, such as estuaries, coastal zones ${ }^{13,14}$, and the base of the euphotic zone in the open ocean ${ }^{15-17}$. These environments also appear to be the frontline of both anthropogenic nitrogen disturbances and ocean warming. Pure cultures of three strains of ammonia-oxidizing archaea (AOA) isolated from marine habitats have shown that AOA growth rates are positively correlated with temperature until their optimum temperatures $\left(T_{\text {opt }}\right)$ are reached ${ }^{18}$. Paradoxically, the limited number of field studies in marine environments ${ }^{19-22}$ produced inconsistent results, i.e. positive and insensitive responses to temperature increase. Due to insufficient field information, how ammonia oxidizers may respond to thermal stress in the vast ocean remains enigmatic, as do possible synergistic effects with continuously increasing anthropogenic nitrogen inputs into the ocean.

To better predict the future of marine nitrogen biogeochemistry, we performed manipulation experiments to characterize the temperature responses of the marine $\mathrm{AO}$ microbial community relative to substrate changes across a broad environmental gradient. Using isotope labeling techniques and a series of temperature/substrate manipulation incubations, we revealed distinct temperature response patterns of marine $\mathrm{AO}$ communities along a substrate gradient from coastal eutrophic waters to offshore oligotrophic regions (Supplementary Fig. 1; Fig. 1; Supplementary Table 1). Our experimental results shed light on the substrateregulated thermal kinetics and parameterization of nitrification that are critically needed for marine biogeochemical models of the rapidly changing marine nitrogen cycle.

\section{Results and discussion}

Distinctive temperature responses along a substrate gradient. Within the temperature range of $\sim 14$ to $\sim 34^{\circ} \mathrm{C}$ in our incubations, the observed AORs at the ambient substrate level

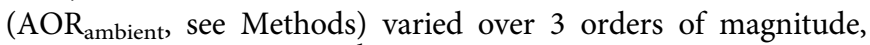
from 0.5 to $\sim 4000 \mathrm{nM} \mathrm{d}^{-1}$, across a wide spectrum of ambient ammonium levels ranging from $14 \mathrm{nM}$ to $96 \mu \mathrm{M}$ (Fig. 1). Three different types of temperature response of $\mathrm{AOR}_{\text {ambient }}$ patterns at estuarine, shelf, and sea basin stations were observed: (I) a positive response with a $T_{\text {opt }}$ of $\geq 34^{\circ} \mathrm{C}$ (Fig. 1a, b); (II) a negative response, which has never been reported before, with a $T_{\text {opt }}$ of $\leq 14^{\circ} \mathrm{C}$ (Fig. 1d-f); and (III) a dome-shaped response with a $T_{\mathrm{opt}}$ of $20-29^{\circ} \mathrm{C}$ (Fig. 1C, g-i).

The Type I pattern was observed at two of the three estuarine stations (JLR1 and JLR2, Fig. 1a, b) where ammonium concentrations were high $(\geq 24 \mu \mathrm{M})$, and the AOR increased linearly as the temperature increased from 14 to $34^{\circ} \mathrm{C}$. In these cases, the $T_{\text {opt }}$ was equal to or higher than the maximum experimental temperature of $34^{\circ} \mathrm{C}$ (Fig. 1a, b). The Type II pattern was observed at the shelf stations (N1, M1, and M2), where $\mathrm{NH}_{4}{ }^{+}$concentrations ranged from 45 to $550 \mathrm{nM}$ (Fig. 1d-f). In contrast to the Type I pattern, the $T_{\text {opt }}$ of the Type II pattern was equal to or lower than the minimum experimental temperature of $14^{\circ} \mathrm{C}$, showing a continuously decreasing AOR as temperature increased. The Type III pattern was observed at station JLR3 (outer estuary), N2 (shelf), N3 and J1 (basin), for which the $T_{\text {opt }}$ of the AOR varied from 20 to $29^{\circ} \mathrm{C}$, with rates decreasing toward both higher and lower temperatures (Fig. 1c, g-i). The $\mathrm{NH}_{4}{ }^{+}$concentrations of the Type III stations ranged from 14 to $5000 \mathrm{nM}$. Nevertheless, the highest $T_{\text {opt }}$ values were observed at coastal sites with the highest ambient ammonium concentrations (Fig. 1).

Substrate regulates AOR and its thermal optimum temperature. For those stations with low ammonium concentrations, the $\mathrm{AOR}$ at in situ temperature increased when the substrate was enriched $\left(\mathrm{AOR}_{\text {enriched }}\right.$, additions of $\left.2000 \mathrm{nM}^{15} \mathrm{NH}_{4}{ }^{+}\right)$(Fig. 1f, i). Meanwhile, the $T_{\text {opt }}$ of the AOR shifted significantly toward higher values ( $t$ test, $p<0.05$; Fig. $1 \mathrm{~d}, \mathrm{f}, \mathrm{g}, \mathrm{i}$ ). Although the resolution of the temperature interval set in our incubation experiments was not high enough to identify a precise $T_{\text {opt }}$ for the AO community, the positive $T_{\text {opt }}$ shift induced by ammonium enrichment was evident.

To further explore how the substrate-regulated $T_{\text {opt }}$ of AOR in marine environments, we designed a Michaelis-Menten (M-M) thermal kinetics experiment for J1 (substrate deprived sea basin) and JLR4 (substrate-replete upstream estuary) stations with distinctive substrate concentrations (see details in Methods). The experimental results revealed that at aiven temperature, the responses of AOR along with substrate addition can be fitted by the classic M-M curve (Fig. 2a, b; Supplementary Table 2), i.e. the rate increased as the $\mathrm{NH}_{4}{ }^{+}$concentration increased until the substrate became saturated. These $\mathrm{M}-\mathrm{M}$ curves are temperaturedependent, with the maximum rate $\left(V_{\max }\right)$ and the halfsaturation constant $\left(K_{\mathrm{m}}\right)$ increasing as the temperature increased until the saturation optimum temperature $\left(T_{\text {opt-sat }}\right)$ was reached (Fig. 2c-f). Note that the $T_{\text {opt-sat }}$ was defined as the optimum temperature of $V_{\max }$ at saturated substrate level $\left(T_{\text {opt-sat }}, \sim 26^{\circ} \mathrm{C}\right.$ for station $\mathrm{J} 1$ and $\sim 29^{\circ} \mathrm{C}$ for JLR4 station; see Fig. 2c, d).

From the above results, we suggest that the $T_{\text {opt-sat }}$ of a singlespecies derived from laboratory culture under a saturated substrate concentration ${ }^{18}$ may not properly represent its $T_{\text {opt }}$ in the field, where ammonium is not always saturated. Some published biogeochemical models with a nitrification component have assumed that nitrification follows the Arrhenius relationship until temperature reaches the $T_{\text {opt }}{ }^{23,24}$. However, the $T_{\text {opt }}$ in these models is derived from pure laboratory cultures typically grown at saturating substrate concentrations ( $\left.T_{\text {opt-sat }}\right)$, which may cause an overestimation of rates in the warming ocean at ambient unsaturated substrate concentrations.

To examine the interactive effects of temperature and substrate on AOR and $T_{\text {opt }}$, we adapted the Dual Arrhenius and Michaelis-Menten kinetics model (DAMM) developed by Davidson et al. ${ }^{25,26}$. The temperature sensitivity of $K_{\mathrm{m}}\left(\mathrm{Q} 10_{\mathrm{Km}}\right)$ and $V_{\max }\left(\mathrm{Q} 10_{\mathrm{V} \max }\right)$ (Fig. 2c-f) was applied. In this model, the 

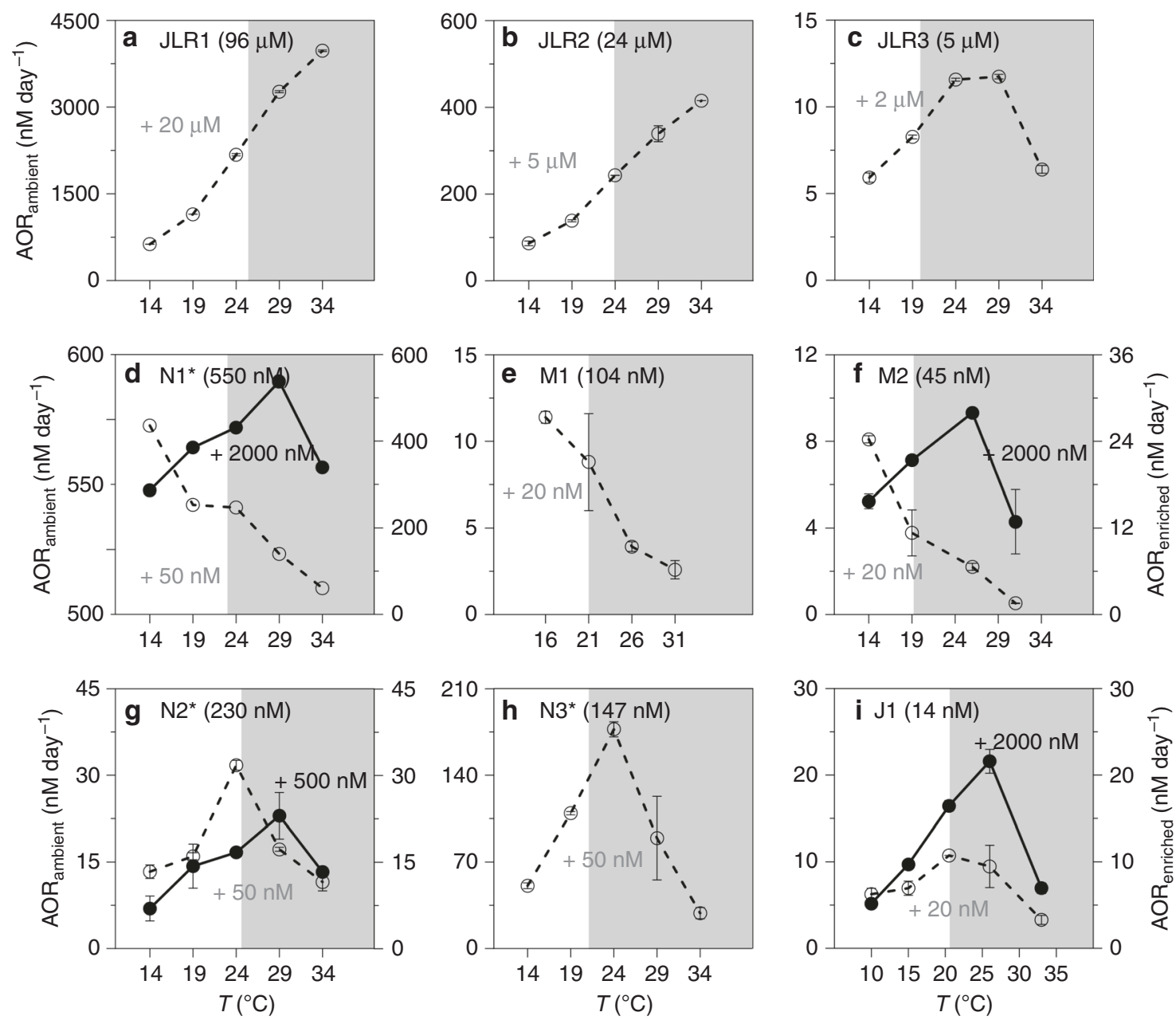

Fig. 1 Thermal responses of ammonia oxidation rates. In situ substrate concentrations are given in parentheses. Ammonia oxidation rates near the ambient substrate level $\left(\mathrm{AOR}_{\text {ambient }}\right)$ are shown as open circles with dashed lines and the enriched substrate level $\left(A O R_{\text {enriched }}\right)$ as solid circles with solid lines. The tracer concentrations of ${ }^{15} \mathrm{NH}_{4}{ }^{+}$added for the ambient and enriched incubations are shown in gray and black numbers, respectively. Gray area denotes temperatures higher than the in situ temperature. The station IDs with asterisk ${ }^{\star}$ ) refer to the stations at which the ammonium concentrations were measured in the shore-based laboratory several days after collection. The rate data are mean values, instead of standard deviation the given bars indicate the variation range of two independent experiments, except N1 station $(n=1)$.

rate was determined by four parameters, i.e. substrate concentration, temperature, Q10 $\mathrm{Km}$, and Q10 ${ }_{\mathrm{Vmax}}$ (see Eq. (7) in Methods). By introducing the $\mathrm{Q} 10_{\mathrm{V} \max }$ and $\mathrm{Q} 10_{\mathrm{Km}}$ values derived from station J1 and JLR4 into the DAMM model, we simulated how AOR responds to substrate and temperature synergistically (Fig. 3; Supplementary Fig. 2). Via the DAMM, we successfully predicted the AOR below the $T_{\text {opt-sat }}$ under various ammonium levels (Fig. 3a, b). Moreover, we developed a $T_{\text {opt }}$ model (see Eq. (9) in Methods) via the DAMM to see if we could predict the $T_{\text {opt }}$ at various substrate levels. For the $T_{\mathrm{opt}}$ model, $T_{\mathrm{opt}}$ increased as substrate concentration increases under the criterion of $\mathrm{Q} 10_{\mathrm{Km}}>$ Q10 Vmax $($ Supplementary Fig. 2). This criterion was fulfilled in both J1 and JLR4 cases (Fig. 2c-f). We see the positive shift of $T_{\text {opt }}$ due to the ammonium addition (up to $\sim 100 \mathrm{nM}$ at J1 station and up to $\sim 10 \mu \mathrm{M}$ at JLR4) can be closely predicted (Fig. $3 \mathrm{c}$, d; Supplementary Fig. 2). Overall, the DAMM model successfully predicts the entire thermal response curve, including rates and $T_{\text {opt }}$, except when the manipulated temperatures exceed $T_{\text {opt-sat }}$ (Fig. 3; Supplementary Fig. 2). AOR drops significantly when temperature is greater than the $T_{\text {opt-sat }}$, so heat-impaired biological enzyme activity ${ }^{27,28}$ might result in deviations from the relationship between $V_{\max }\left(K_{\mathrm{m}}\right)$ values and temperature from the Arrhenius law.
The substrate-dependent thermal optimum is attributable to the effect of temperature on biochemical kinetics and the structural stability of the enzymes. Increasing temperature promotes catalytic rate, thus, $V_{\max }$ increases due to increasing kinetic energy of reactants and rates of collision, as well as higher structural flexibility of enzymes ${ }^{27,29}$. However, higher structural flexibility (lower stability) also results in active sites with a reduced ability for ligand recognition and binding, therefore, lower kinetic efficiency. Accordingly, one important physiological response of an organism to rising temperature will be a reduction in substrate affinity (Supplementary Table 2), and thus higher substrate demands (i.e. higher $K_{\mathrm{m}}$ value) ${ }^{25,29-31}$. In other words, higher substrate levels help to compensate for enzyme structural stability losses and so promote growth rates at higher temperature. Note that some other microbes may respond differently to temperature, with $\mathrm{Q} 10_{\mathrm{Km}} \leq \mathrm{Q} 10_{\mathrm{V} \max }$ for instance. This may lead to predictable yet unidirectional rate increases in response to warming (without substrate-regulated $T_{\text {opt }}$ ) until the $T_{\text {opt-sat }}$ is reached, regardless of substrate changes.

Similarly, nutrient-dependent $T_{\mathrm{opt}}$ has been reported for phytoplankton growth in pure cultures previously. For instance, Thomas et al..$^{32}$ indicated that the $T_{\text {opt }}$ for growth of a marine diatom was a saturating function of major nutrient (nitrate and 

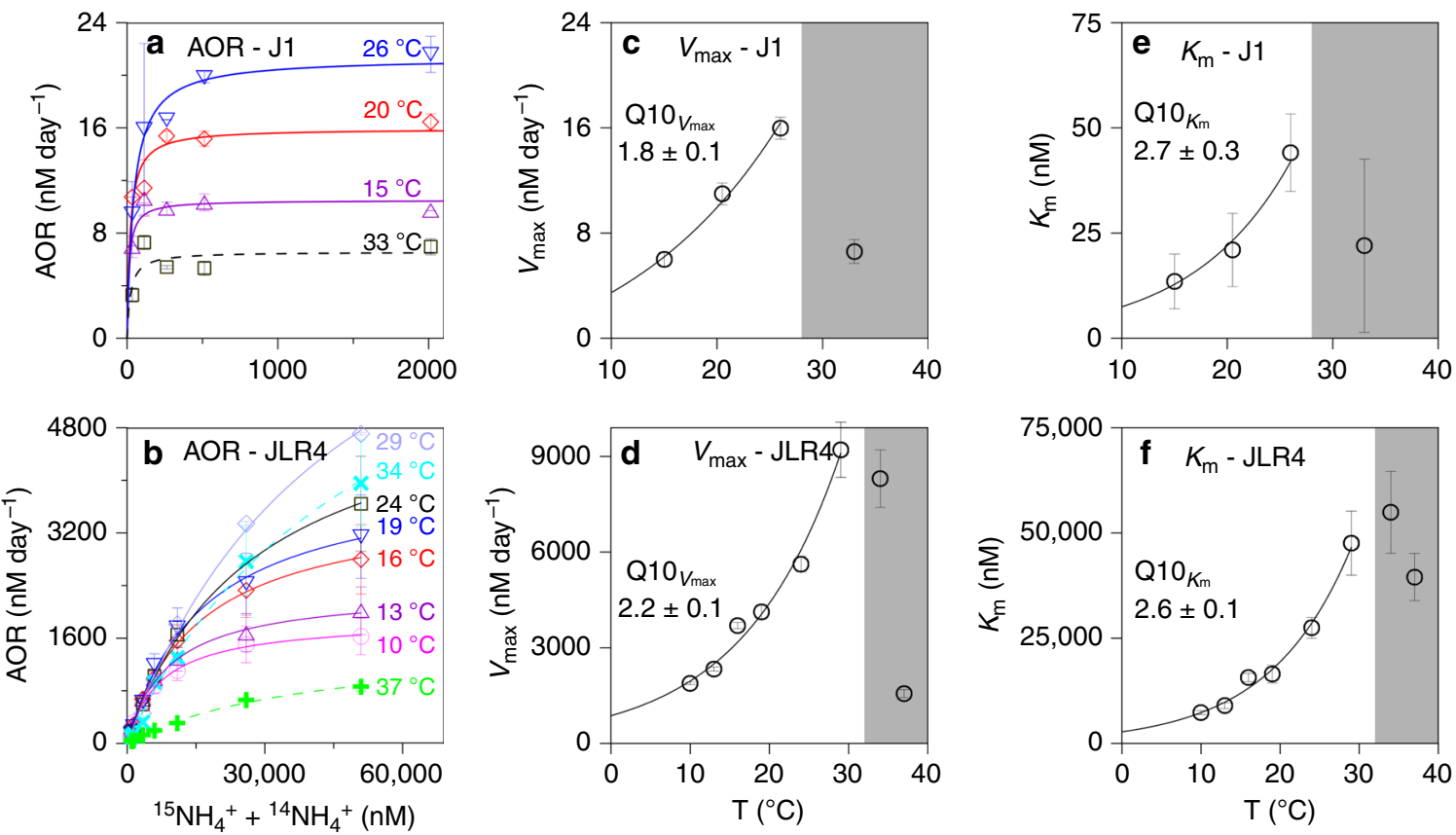

Fig. 2 Thermal kinetics plots for ammonia oxidation rates. $\mathbf{a}, \mathbf{b}$ Michaelis-Menten kinetics of ammonia oxidation rates in response to changes in temperature. c-f Arrhenius model fitting curves for the experimental $V_{\max }\left(\mathrm{J} 1: Y=(4.1 \pm 0.7) \times(1.8 \pm 0.1)^{\mathrm{T} / 10}, R^{2}=0.99 ; J \mathrm{LR} 4: Y=(869.9 \pm 118.2) \times(2.2 \pm\right.$ $\left.0.1)^{T / 10}, R^{2}=0.98\right)$ and $K_{\mathrm{m}}\left(\mathrm{J} 1: Y=(2.6 \pm 1.1) \times(2.7 \pm 0.3)^{T / 10}, R^{2}=0.98 ; J L R 4: Y=(2765.7 \pm 404.6) \times(2.6 \pm 0.1)^{T / 10}, R^{2}=0.99\right)$ of the ammonia oxidation rate as a function of temperature. Color curves in $(\mathbf{a}, \mathbf{b})$ represent the regression curves of the Michaelis-Menten kinetics at various temperatures. Fitting curves in (c-f) are for data points lower than the optimum temperature in substrate-saturated conditions $\left(T_{\text {opt-sat, }} \sim 26^{\circ} \mathrm{C}\right.$ for station $\mathrm{J1} ; 29^{\circ} \mathrm{C}$ for station JLR4). Solid lines in (a, $\left.\mathbf{b}\right)$ and the white areas in (c-f) represent the Michaelis-Menten kinetics at temperatures lower than the $T_{\text {opt-sat. }}$ While dotted lines in $(\mathbf{a}, \mathbf{b})$ and the gray areas in $(\mathbf{c}-\mathbf{f})$ represent the Michaelis-Menten kinetics at temperatures greater than the $T_{\text {opt-sat. }}$ See Supplementary Table 2 for more details on the temperature dependence of $K_{m}$ and $V_{\text {max }}$. The data in (a) are presented as mean values, instead of standard deviation the given bars indicate the variation range of two independent experiments. Data in (b-f) are expressed as the mean values \pm SD ( $n=6$ in $(\mathbf{b})$; $n=10$ in (c, e); $n=48$ in (d, f); independent experiments).

phosphate) concentration, and that the $T_{\text {opt }}$ could decrease by $3-6{ }^{\circ} \mathrm{C}$ at low concentrations relative to that at saturated nutrient levels. In addition to studies of pure cultures, field studies have also suggested that organisms may tolerate higher temperature stresses when nutrients are more abundant. For example, kelp (Laminaria saccarina) with high nitrogen reserves have more capacity for thermal adaptation ${ }^{33}$, while corals with symbionts limited by phosphate are more susceptible to heat-induced bleaching 34 . Although these examples are functionally and taxonomically distant from AOA and ammonia-oxidizing bacteria (AOB), strong similarities in substrate/nutrient regulation characteristics may imply a similar mechanism of enzymatic thermal responses between chemoautotrophs and photoautotrophs.

Nevertheless, the higher thermal optimum of $\mathrm{AO}$ in the estuarine system (e.g., JRL1, JLR2, and JLR3) than in the offshore environment (e.g., N3 and J1) can be explained by a substrateregulated $T_{\text {opt }}$. Note that field AOR represents explicitly the collective activity of the AO community composed of AOA and $\mathrm{AOB}$, which may have distinctive thermal tolerances and affinities for substrate. Therefore, community structure very likely plays a role in modulating the thermal response patterns of community $\mathrm{AOR}$ in the field environments, in addition to substrate concentration.

Rate proportion and community thermal optimum. To further examine to what extent the community structure (proportions of $\mathrm{AOA}$ and $\mathrm{AOB}$ ) might shape the thermal response patterns of community AOR observed in the field, we added allylthiourea (ATU) to inhibit the activity of AOB for rate discrimination (see
Methods; Supplementary Discussions). Results showed that the inhibitory efficiency of AOR was gradually reduced with increasing offshore distance (Fig. 4). That is, from the estuary (JLR4, JLR1, JLR2, and JLR3) to the shelf (N1 and N2) and the sea basin (N3), the relative contribution of AOB to the community AOR dropped from as high as $\sim 100 \%$ in the upper estuary down to $\sim 70 \%$ in the shelf transition zone, and near $0 \%$ in the basin. Meanwhile, the AOA/AOB gene copies data (see Supplementary Methods) from estuary to sea basin (Fig. 4) also clearly show that the abundance of AOA relative to AOB increased exponentially with increasing offshore distance. A similar offshore pattern of community distribution was also observed in other regions, such as from the Pearl River estuary to the South China Sea ${ }^{35}$, and from the freshwater region of the Chesapeake Bay to the coastal and open ocean water column ${ }^{36}$. This pattern suggests that AOB strongly prefer substrate-replete niches, and vice versa for $\mathrm{AOA}^{20,37}$, agreeing well with our $\mathrm{M}-\mathrm{M}$ experimental data that the substrate saturation condition for AOB-dominated water at JLR4 was several orders of magnitude higher than that for AOAdominated water from J1 (Supplementary Table 2). The $K_{\mathrm{m}}$ values of AOB in JLR4 varied from 7 to $55 \mu \mathrm{M}$ in accordance with varying temperatures from 10 to $37^{\circ} \mathrm{C}$, while the $K_{\mathrm{m}}$ values of AOA in J1 varied from 13 to $44 \mathrm{nM}$ over a similar temperature range (Supplementary Table 2). Results were supportive of previous pure culture and field studies which showed the minimum ammonium demand for $\mathrm{AOB}$ is $>1 \mu \mathrm{M}$ and $K_{\mathrm{m}}$ values range from 28 to $4000 \mu \mathrm{M}^{38-41}$, while minimum ammonium demand and $K_{\mathrm{m}}$ value for AOA are $<10$ and $133 \mathrm{nM}^{42}$, respectively.

The low $K_{\mathrm{m}}$ for AOA indicates that the ambient substrate concentration can easily reach saturation state for AOA-dominated 

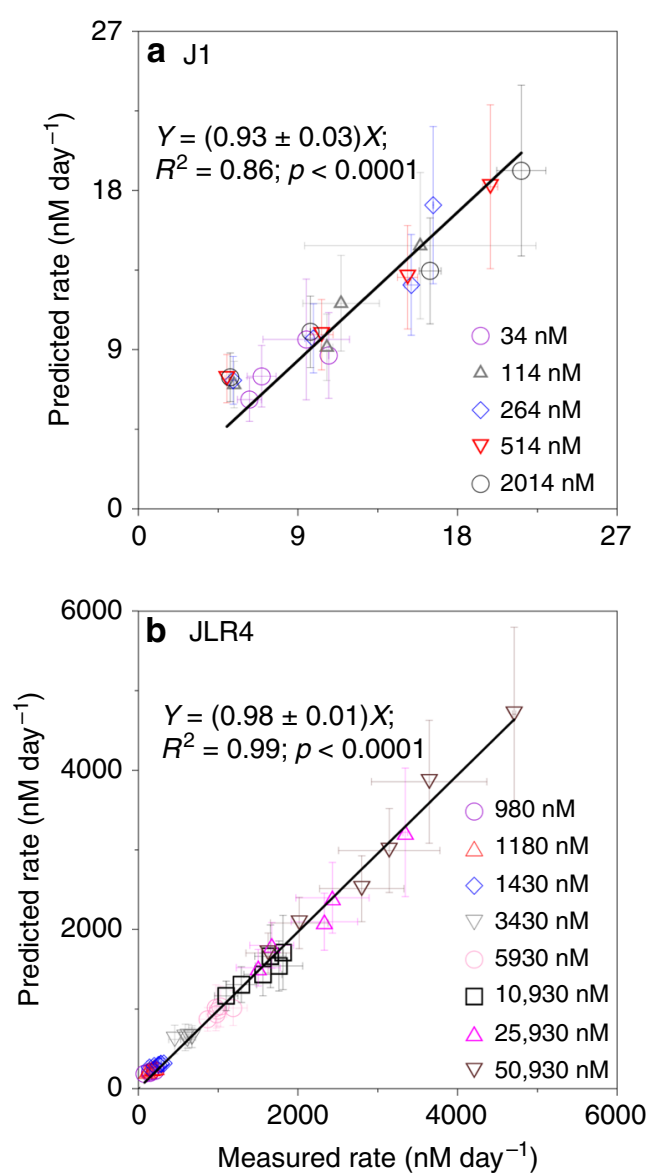
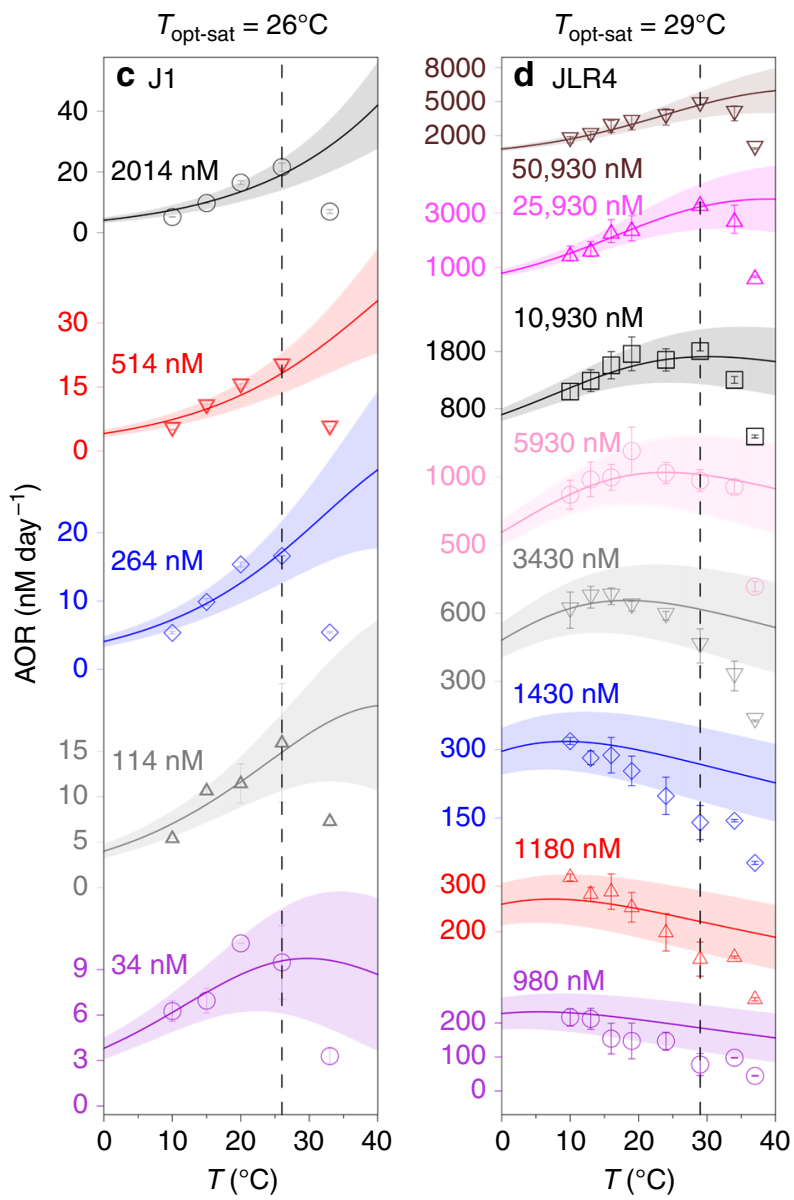

Fig. 3 Validation plot for the rate predictions and observations. $\mathbf{a}, \mathbf{b}$ Scatter plot of the predicted rates via the Dual Arrhenius and Michaelis-Menten kinetics model (DAMM model) and the measured rates under different substrate concentrations and temperatures (below the optimum temperature in substrate-saturated conditions, $T_{\text {opt-sat }}$ ). Linear regressions between the model predictions and the measurements are presented (two-sided $t$ test was used to generate the $p$ value ( $95 \%$ confidence) to measure the strength of correlation coefficient. $p$ values are uncorrected). c, $\mathbf{d}$ The rate patterns (dots) against temperature under different substrate concentrations. Curves stand for the predicted rates derived from the DAMM model and the symbols represent the measured rates. The shades denote the uncertainty of model prediction. The dashed black vertical lines represent the $T_{\text {opt-sat. }}$ The measured rates in $(\mathbf{a}, \mathbf{c})$ are presented as mean values, instead of standard deviation the given bars indicate the variation range of two independent experiments. The measured rates in $(\mathbf{b}, \mathbf{d})$ and the predicted rates in (a-d) are expressed as the mean values \pm SD ( $n=10$ in $(\mathbf{a}, \mathbf{c}) ; n=48$ in $(\mathbf{b}, \mathbf{d})$; independent experiments).

basin regions (see $K_{\mathrm{m}}$ values in Supplementary Table 2), thus, leading to a dome-shape thermal response pattern with the $T_{\text {opt }}$ near to $T_{\text {opt-sat }}$ likely around $26^{\circ} \mathrm{C}$ (Figs. $1 \mathrm{~h}, \mathrm{i}, 3 \mathrm{c}$ ), consistent with a report for an AOA isolate in lab culture ${ }^{18}$. Meanwhile, a $T_{\text {opt-sat }}$ of $\sim 30^{\circ} \mathrm{C}$ (Figs. 1a, b, 3d) falls within the range of $29-35^{\circ} \mathrm{C}$ reported for AOBs in pure culture ${ }^{43,44}$. Since the AOB-dominated JLR4 case showed a very wide $T_{\text {opt }}$ as substrate varied, the negative response patterns at temperatures between 10 and $30^{\circ} \mathrm{C}$ can be seen when the substrate was diluted below the several $\mu \mathrm{M}$ level, mimicking the seaward advection of a water mass and subsequent substrate dilution. Accordingly, we speculate that the three types of AOR thermal response patterns observed in the field were a result of the combined thermal response patterns of $\mathrm{AOB}$ and $\mathrm{AOA}$ along the substrate gradient. Although this type of negative response pattern has never been reported before in the field, we observed it at shelf stations and in our dilution experiment. This suggests that when AOBs dominate the community AOR in the shelf transition zone (Fig. 4), community AOR may respond negatively to temperature rise due to a low $T_{\mathrm{opt}}$ under substrate stress. In fact, comparison of the community AOR between ambient conditions $\left(20 \mathrm{nM}^{15} \mathrm{NH}_{4}{ }^{+}\right)$ and after significant tracer addition $\left(2000 \mathrm{nM}^{15} \mathrm{NH}_{4}{ }^{+}\right)$, we can clearly see the magnitude of rate stimulation at in situ temperature was higher at the shelf station dominated by AOB (M2 station, Fig. 1f) than at the basin station (J1 station, Fig. 1i) where the AOR was dominated by AOA. Such distinct rate stimulations by substrate additions implicitly indicate the degree of substrate saturation was lower on the shelf, where AOB contributed more to the AOR.

Global change and future nitrification. Sea surface temperature (SST) will inevitably increase in most of the ocean as atmospheric greenhouse gas concentrations continue rising. According to the 2013 Intergovernmental Panel on Climate Change Representative Concentration Pathways (RCP) 8.5 scenario, mean global sea surface temperature (SST) will increase by up to $4^{\circ} \mathrm{C}$ by the year $2100^{45}$, equivalent to a rise of $0.04^{\circ} \mathrm{C} / \mathrm{y}$. The seasonal temperature ( $1 \mathrm{~m}$ depth) ranges from 13 to $32^{\circ} \mathrm{C}$ for the Jiulong River estu$\operatorname{ary}^{46}$ (Supplementary Fig. 1; Supplementary Table 3). The average SST rise over the period of 1960-2010 in the studied area was $0.02{ }^{\circ} \mathrm{C} / \mathrm{y}^{47}$, about half of the predicted maximum increase rate of the global mean. On the other hand, hydrography of the northern South China Sea is influenced by regional climate and local 
hydrodynamics, including the western boundary current intrusion, internal waves and monsoon winds ${ }^{48}$. The water temperature of the upper $200 \mathrm{~m}$ in the northern South China Sea ranges from 13 to $31{ }^{\circ} \mathrm{C}$ at different depths ${ }^{48,49}$ and the mean temperature rise for the entire $200 \mathrm{~m}$ water column in the studied area was reported to be $0.09^{\circ} \mathrm{C} / \mathrm{y}$ from 1975 to $2005^{50}$. Generally speaking, the rise of water temperature in our study region is similar to or even larger than the global mean, suggesting this global warming rate can be applied in our study area (see Supplementary Discussion).

Using the thermal responses of kinetic parameters, we try to evaluate warming effects on the competition between $\mathrm{AOB}$ and AOA. The specific affinity $(\alpha)$, the ratio of $V_{\max } / K_{\mathrm{m}}$, can be used to represent a microbe's ability to scavenge substrate from dilute

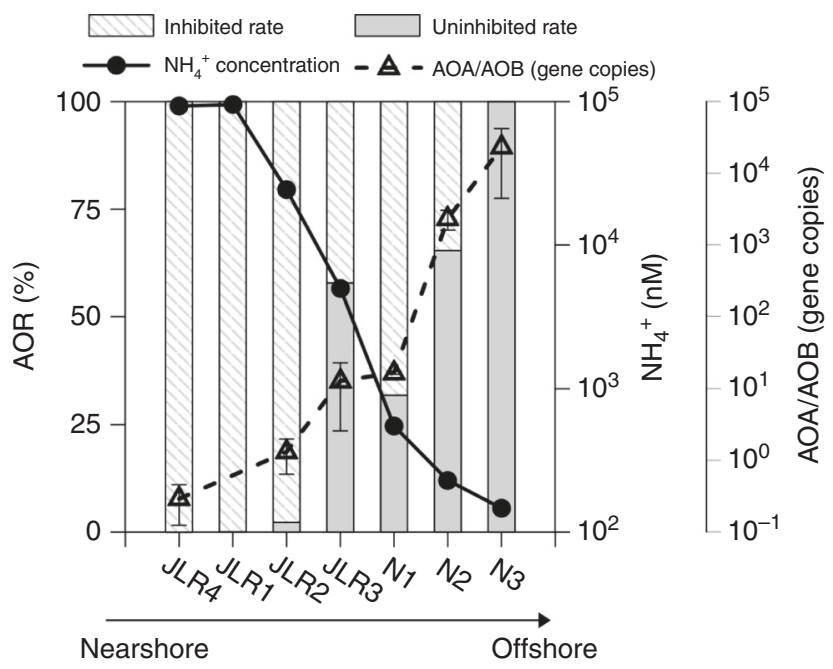

Fig. 4 Rate inhibition along a substrate gradient. Proportional contributions of inhibited (slashed bars) and uninhibited (gray bars) ammonia oxidation rate by allylthiourea (ATU) to the bulk ammonia oxidation rate, the in situ ammonium concentration (solid line/filled circles) and the ratios of ammonia-oxidizing archaeal $(A O A)$ vs. bacterial (AOB) amoA gene copy numbers (dashed line/open triangles). The gene copies data are expressed as the mean values \pm SD ( $n=3$ independent experiments). environments. Thus, microorganisms with higher a values are superior competitors when substrate is limiting. We found the specific affinity was higher for AOA-dominated J1 than for AOBdominated JLR4 (Supplementary Table 2; Fig. 5a). Moreover, a values of $\mathrm{AOB}$ vary in a narrower range relative to those of $\mathrm{AOA}$ as temperature changes. The less variable a may reflect that $\mathrm{AOB}$ cope better with variable temperature in their habitat (Supplementary Table 2; Fig. 5a). In contrast, AOA are more sensitive to temperature change. As aforementioned in the DAMM model, the criterion to have substrate-dependent $T_{\text {opt }}$ is $\mathrm{Q} 10_{\mathrm{Km}}>$ Q10 ${ }_{\text {Vmax }}$, which also results in a reduction in a during warming for both AOA and AOB. Yet, the relative reduction in AOA specific affinity as temperature increases is more significant (Fig. 5a), suggesting AOAs are more competitive in low temperature environments relative to AOBs, and so may not be favored in a warming ocean. On the other hand, the specific affinity of AOBs is insensitive to temperature change, suggesting their adaptation to nearshore environments with greater temperature fluctuation. The seaward gradient in temperature fluctuations and ammonium concentrations determine the nitrifier community, thus, thermal response pattern of community AOR observed in the field.

To predict the trends of AOR in different geographic spaces in warming ocean, we compile the available marine AOR data to examine the AOR changes empirically. If we assume the biogeographic distribution of $\mathrm{AO}$ community remains unchanged and consider solely the warming effect on AOR relative to the onsite temperature, we found the thermal responses of AOR in nearshore and offshore are quite different (Fig. 5b). More specifically, the higher $T_{\text {opt }}$ of these $\mathrm{AO}$ communities in nearshore regimes allows ocean warming to promote coastal AOR when the temperature change increment is $<10^{\circ} \mathrm{C}$. The AOR then drops with further temperature increases, likely due to the impaired enzyme activity as discussed above. On the other hand, community AOR decreases linearly with warming (Fig. 5b) in offshore waters, mainly because current ambient temperatures are close to $T_{\text {opt-sat }}$ for AOAs and/or higher than $T_{\text {opt }}$ of AOB in low substrate state.

According to the mean global sea surface temperature increase of $4{ }^{\circ} \mathrm{C}$ by 2100 , AOR might increase by $0.4-30 \%$ in nearshore systems, with a mean increase of $13 \%$ (Fig. 5b). However, at contemporary substrate levels the community AOR in oligotrophic environments would decline by $13-33 \%$, with a mean
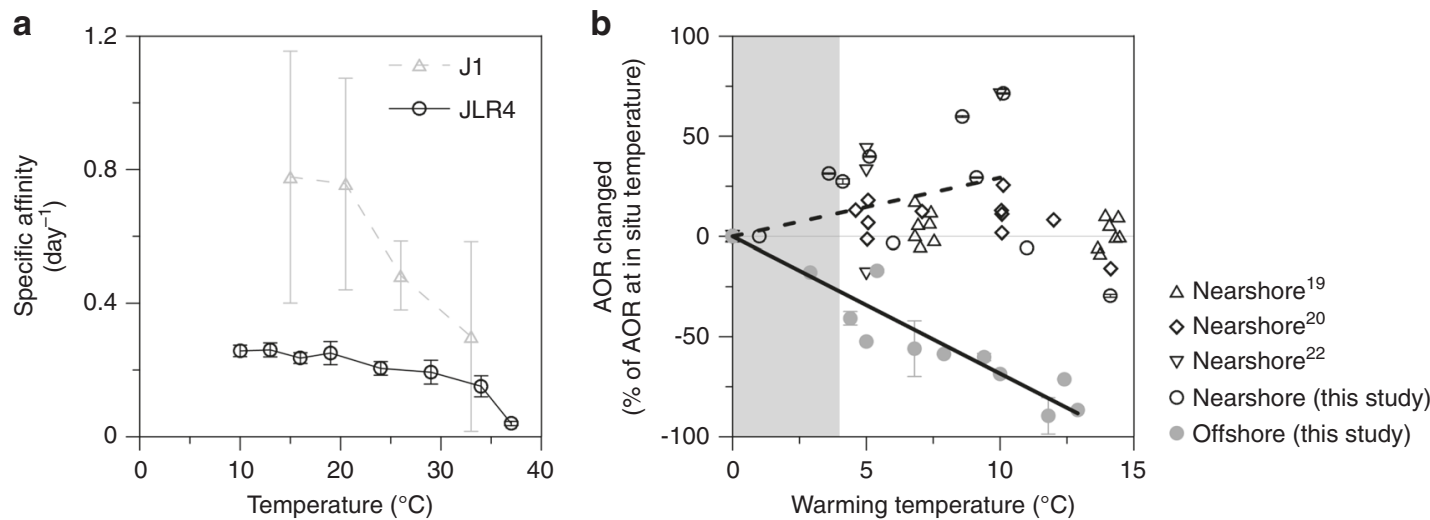

Fig. 5 Thermal response projections in near- and offshore regions. a The thermal responses of specific affinity at the J1 and JLR4 stations. Data are expressed as the mean values \pm SD ( $n=10$ in J1 station; $n=48$ in JLR4 station; independent experiments). b Normalized warming-driven variations in ammonia oxidation rates. Rate changed (\%) is relative to the ammonia oxidation rate (AOR) at in situ temperature. The mean increase (nearshore hollow dots) is denoted by the dashed line and the mean reduction (offshore, solid dots) is denoted by the solid black line. The shaded area represents the $4{ }^{\circ} \mathrm{C}$ increase in temperature mentioned in the IPCC study. Note that the stations where the surface salinities are lower than 32 are classified as nearshore station, and the others are classified as offshore stations. The data in (b) are presented as mean values, instead of standard deviation the given bars indicate the variation range of two independent experiments. 
decrease of $27 \%$ in response to the $4{ }^{\circ} \mathrm{C}$ warming in ocean temperature (Fig. 5b).

Our results also suggest that the projected gradual increase in atmospheric deposition of anthropogenic nitrogen (including ammonium $)^{7,51,52}$ may aid in the thermal adaption of ammoniaoxidizing microorganisms in ammonium-depleted offshore environments. However, most of the $\mathrm{NH}_{4}+$ from the atmosphere will be utilized first by phytoplankton in the surface layer above the nitracline, due to a competitive advantage of phytoplankton toward $\mathrm{NH}_{4}{ }^{+}$relative to nitrifers ${ }^{17,53}$. If this ammonium was to be supplied directly to the niche of AOA, the offshore AOR may response positively to warming before reaching the $T_{\text {opt-sat }}$. Note that AOAs prefer low temperature and cope with low substrate, so the peak AOR in open ocean generally appears near the nitracline ${ }^{17}$ where the vertical temperature gradient is also large. Therefore, the warming effect may also have a differential influence across the vertical scale.

In contrast, in the shallow nearshore dominated by AOBs additional inputs of anthropogenic $\mathrm{NH}_{4}{ }^{+}$cannot further promote $T_{\text {opt-sat }}$ to alter the empirical trend. Thus, a positive temperature response in nearshore regimes is more certain. According to our observational data (Fig. 4), although AOB gene copies are much less, AOBs appear to be the major AOR contributor in the midto-lower estuary, coastal seas and even in shelf zones unless ammonium is down to approximately hundreds of $\mathrm{nM}$ level. Thus, we speculate the niche space of AOBs may expand in the future in the land-ocean transition zone, because of their greater thermal adaptability and continuously increasing anthropogenic nitrogen inputs from continents.

The observed differential warming effects on eutrophic nearshore systems and oligotrophic offshore regions would have significant implications for climate feedbacks of the marine nitrogen cycle over a wide trophic range. For example, AOR increases in the coastal ocean would subsequently promote $\mathrm{N}_{2} \mathrm{O}$ emissions. In fact, field and laboratory culture studies showed that $\mathrm{AOB}$ have a greater potential than AOA to generate $\mathrm{N}_{2} \mathrm{O}$. The $\mathrm{N}_{2} \mathrm{O}$ yield from $\mathrm{AOB}$ is approximately two times higher than that of AOA cultures ${ }^{54}$. Thus, in the nearshore where AOBdominated AOR, $\mathrm{N}_{2} \mathrm{O}$ production may be further enhanced. This would serve as a positive feedback for global warming, while the suppression of AOR in offshore regions creates a negative feedback. On the other hand, during nitrogen recycling in turbid coastal and estuary systems, increasing $\mathrm{AO}$ would potentially enhance $\mathrm{NO}_{2}{ }^{-} / \mathrm{NO}_{3}{ }^{-}$production to fuel denitrification in microniches ${ }^{55}$, which is another important pathway for $\mathrm{N}_{2} \mathrm{O}$ production. Thus, warming and excessive nitrogen input would further exacerbate the emissions of $\mathrm{N}_{2} \mathrm{O}$ from coastal seas.

In addition to climate feedbacks, the impact of global warming on oceanic ammonia oxidation may also change the distribution of nitrogen species. The suppression of $\mathrm{AO}$ by ocean acidification $^{8}$ was also reported to further exacerbate the inhibition of $\mathrm{AO}$ caused by warming. At the base of the euphotic zone in the stratified open ocean, this dual suppression of $\mathrm{AO}$ will substantially reduce the amount of $\mathrm{NH}_{4}{ }^{+}$converted back to $\mathrm{NO}_{3}{ }^{-}$by nitrification, ultimately favoring smaller primary producers that are more competitive for $\mathrm{NH}_{4}{ }^{+}$rather than $\mathrm{NO}_{3}{ }^{-}$. Meanwhile, $\mathrm{NO}_{3}{ }^{-}$-supported primary producers, such as large diatoms, would be at a competitive disadvantage. This might be disadvantageous for carbon export to the deep sea, and thus constitute a positive feedback to global warming.

Of course, multiple environmental factors such as acidification, stratification, deoxygenation, and UV light are changing simultaneously. To better predict how nitrification responds to interactive global change forcing, multiple factors should be included in experiments in the future. Moreover, both field and laboratory $\mathrm{AO}$ responses of the two steps of nitrification and associated $\mathrm{N}_{2} \mathrm{O}$ yield should also be investigated at various levels of ammonium to assess their impacts on global warming. Meanwhile, genomic and proteomic information is urgently needed to determine the physiological mechanisms of the speciesspecific temperature responses of marine $\mathrm{AO}$ organisms. Besides nitrification, to improve model predictive ability and have indepth understanding of the biogeochemical role of nitrogen in microbial ecosystems, the temperature sensitivity of kinetic parameters of associated nitrogen processes needs to be investigated. Moreover, it is important to carefully examine the extrapolation from short-term experiments, such as our hourly manipulations, to long-term microbial responses to environmental change (decades). Analogous long-term experiments (thousands of generation) for marine nitrifiers are needed to explore the possibility of evolutionary adaptation to simultaneous changes in ammonium supplies and temperature in the future ocean.

\section{Methods}

Sampling. Samples were collected during five field cruises in 2016-2020. The sampling sites ranged from estuarine (the Jiulong River) to sea basin (the South China Sea) sites (Supplementary Fig. 1). Water samples were collected near the bottom of the euphotic zone where ammonia oxidation is the most active. The detailed sampling information, including sampling dates and depths, is reported in Supplementary Table 1. For the South China Sea cruises in May 2016, November 2016, and June 2017, the seawater samples were collected using a conductivity-temperature-depth (CTD) rosette fitted with 12-L Niskin bottles. Acid-washed high-density polyethylene (HDPE) bottles were used to collect the samples. A $100 \mathrm{~mL}$ portion of each nutrient sample from each station was analyzed for concentrations on-deck within hours of collection. At each sampling site, 5-10 L of water was collected for the manipulation experiments. During the Jiulong River cruise, samples were collected using a low-pressure electric bilge pump to gently draw water through acid-washed Tygon tubing into $10 \mathrm{~L}$ acid-washed polycarbonate (PC) bottles. After collection, these samples were stored in the dark and were transported to the shore-based laboratory within $6 \mathrm{~h}$ for the incubation experiments. For nutrient analyses, $100 \mathrm{~mL}$ of water was filtered $(0.2 \mu \mathrm{m})$ and frozen at $-20^{\circ} \mathrm{C}$ in the laboratory.

Chemical analyses. Salinity and temperature were measured using a CTD profiler During the South China Sea cruises, the ammonium concentrations were measured immediately on-deck (except stations N1, N2, N3) using the fluorescence detection method $^{56}$ with a detection limit of $\sim 5 \mathrm{nM}$. The ammonium concentrations of the Jiulong River samples were measured using the indophenol blue spectrophotometric method ${ }^{57}$ with a detection limit of $0.6 \mu \mathrm{M}$. The nitrite and nitrate concentrations $\left(\mathrm{NO}_{\mathrm{x}}{ }^{-}\right)$were measured using the chemiluminescence technique ${ }^{58}$ with a $0.01 \mu \mathrm{M}$ detection limit.

Ammonia oxidation rate incubation experiments. ${ }^{15} \mathrm{~N}$-labeled ${ }^{15} \mathrm{NH}_{4} \mathrm{Cl}(98$ atom\% ${ }^{15} \mathrm{~N}$; Sigma-Aldrich, 299251-1G, Lot\#TA2540V) was added to the water samples to determine the ammonia oxidation rates. The final concentrations of ${ }^{15} \mathrm{NH}_{4} \mathrm{Cl}$ are reported in Fig. 1.

The South China Sea and Jiulong River samples were incubated in the dark (1-2 replicates) for $\sim 24 \mathrm{~h}$ and $\sim 3 \mathrm{~h}$, respectively. Detailed information about this method has been presented in previous studies ${ }^{59,60}$. The control samples were filtered immediately $\left(t_{0}\right)$ after tracer addition. All of the incubation procedures were terminated by filtering samples through a $0.22 \mu \mathrm{m}$ polycarbonate membrane, and the filtrate was frozen at $-20^{\circ} \mathrm{C}$ until analysis. To examine the linearity of the ${ }^{15} \mathrm{NO}_{\mathrm{x}}{ }^{-}$production within the incubation period, we carried out time series incubation experiments for samples from both estuary and sea basin stations (Supplementary Fig. 1 and Supplementary Fig. 3). Highly correlated linear regressions for time series incubations suggest the isotope dilution effect and community changes were minimal within the incubation periods.

The final added tracer concentration of $<2$ times the in situ ammonium concentration was defined as the ammonia oxidation rates for the ambient substrate level $\left(\mathrm{AOR}_{\mathrm{ambient}}\right)$. Higher additions were defined as the ammonia oxidation rates at the enriched substrate level ( $\left.\mathrm{AOR}_{\text {enriched }}\right)$.

Temperature manipulation experiments. To quantify the effect of temperature on $\mathrm{AO}$, we applied a gradient of $4-5$ temperatures ranging from $\sim 14$ to $\sim 34^{\circ} \mathrm{C}$ at $\sim 5^{\circ} \mathrm{C}$ intervals (Fig. 1). The temperature was controlled by a thermostat-controlled incubator with a precision of $\pm 1{ }^{\circ} \mathrm{C}$.

Michaelis-Menten kinetics experiments. We conducted experiments to determine the Michaelis-Menten kinetics of ammonia oxidation in response to 
temperature. For the basin area where $\mathrm{NH}_{4}{ }^{+}$concentration was low, such as station J1, we added substrate directly to obtain $\mathrm{M}-\mathrm{M}$ curves under manipulated temperatures. Varied ammonium concentrations were recorded for water samples incubated for $\sim 24 \mathrm{~h}$ at different temperatures (Fig. $2 \mathrm{a}$ ). In areas where AOB dominated, such as in JLR4 estuary, the concentration of substrate was over the saturation concentration of $\mathrm{AOB}$ (dozens of $\mu \mathrm{M}$ levels). To test how field $\mathrm{AOB}$ respond to temperature change in low substrate and to obtain the $\mathrm{M}-\mathrm{M}$ kinetic parameters of $\mathrm{AOB}$ collected from the field, we tried to dilute the ammonium in the freshwater water sample collected from the very upper estuary. The procedure is as follows: (1) we collected microbes from 15-L seawater by using $0.2 \mu \mathrm{m} \mathrm{PC}$ membrane, which might enrich the ammonia-oxidizing microorganisms, and then (2) all microbes on the membrane were washed into the mixture of $50 \mathrm{~mL}$ in situ seawater and $5 \mathrm{~L}$ Milli-Q water (diluted 100 times), (3) a wide gradient of $\mathrm{NH}_{4}{ }^{+}$ concentration was added afterward for $\mathrm{M}-\mathrm{M}$ kinetics experiments under manipulated temperatures (Fig. 2b).

Inhibition experiments. In an attempt to distinguish the relative contributions of archaeal and bacterial ammonia oxidation, parallel incubations with ${ }^{15} \mathrm{NH}_{4}{ }^{+}$and $80 \mu \mathrm{M}$ allylthiourea (ATU) were conducted at station JLR1, JLR2, JLR3, JLR4, N1, N2, and N3 (Fig. 4). ATU was utilized to inhibit $\beta$-proteobacterial AOB with minimal effects on AOA at the concentration in our incubations $(\sim 80 \mu \mathrm{M})^{61}$. Thus, rates of ammonia oxidation in samples tested with ATU are the rates of AOA obtained by suppressing AOB. The rates of $\mathrm{AOB}$ were then derived by difference from the control without ATU addition.

Measurement of ammonia oxidation rate. The $\delta^{15} \mathrm{~N}$ of the $\mathrm{NO}_{\mathrm{x}}{ }^{-}$, end product of ammonia oxidation, was determined using the denitrifier method ${ }^{62,63}$. The isotopic composition of the bacterially-produced $\mathrm{N}_{2} \mathrm{O}$ was measured using a Gasbench-II (Thermo Fisher) connected to an isotope ratio mass spectrometer (Thermo Delta $\mathrm{V}$ Advantage). In order to obtain accurate $\delta^{15} \mathrm{~N}$ values, three $\mathrm{NO}_{3}{ }^{-}$international reference materials $\left(\delta^{15} \mathrm{~N}_{\text {USGS } 34}=-1.80 \%\right.$, $\delta^{15} \mathrm{~N}_{\text {IAEA N3}}=4.70 \%$, and $\delta^{15} \mathrm{~N}_{\text {USGS }}$ ${ }_{32}=180.00 \%$ ) were used to calibrate the $\delta^{15} \mathrm{~N}-\mathrm{NO}_{\mathrm{x}}{ }^{-}$of the samples. The detection limit was an absolute amount of $4 \mathrm{nmol} \mathrm{N}$, and the precision of $\delta^{15} \mathrm{~N}$ was $0.2 \%$.

The rate was calculated using Eq. (1) ${ }^{16,64}$ :

$$
\mathrm{AOR}=\frac{\Delta\left[{ }^{15} \mathrm{NO}_{\mathrm{X}}^{-}\right]}{\mathrm{f}_{15} \mathrm{NH}_{4}^{+} \times t}
$$

where $\Delta\left[{ }^{15} \mathrm{NO}_{\mathrm{x}}{ }^{-}\right]$is the change in concentration of ${ }^{15} \mathrm{NO}_{\mathrm{x}}{ }^{-}$between the start and the end of the incubation due to ammonia oxidation; $\mathrm{f}^{15} \mathrm{NH}_{4}{ }^{+}$is the fraction of ${ }^{15} \mathrm{NH}_{4}{ }^{+}$labeled with ${ }^{15} \mathrm{~N}$ at the start of the incubation; and $t$ is the length of incubation.

Note that the incubation experiments were conducted in different cruises. During one of the cruises, we did not have sufficient manpower to do on-deck $\mathrm{NH}_{4}{ }^{+}$measurements (marked by ${ }^{*}$ for stations N1, N2, and N3 in Fig. 1). The $\mathrm{NH}_{4}{ }^{+}$concentrations determined might be higher in lab than on-deck measurements. The influence will be a significant overestimate in $\mathrm{AOR}_{\text {ambient }}$ but insignificant overestimate in $\mathrm{AOR}_{\text {enriched. }}$ Thus the response patterns were utilized for discussion while the substrate enrichment effect is not discussed.

The DAMM model and $\boldsymbol{T}_{\text {opt }}$ model. The Dual Arrhenius and Michaelis-Menten kinetics model (DAMM) was initially introduced by Davidson et al. ${ }^{25,26}$. The initial model combined the Michaelis-Menten (Eq. (2)) and temperature sensitivities of maximum rate $\left(V_{\max }\right.$, Eq. (3)) and half-saturation constant $\left(K_{\mathrm{m}}\right.$, Eq. (4))

$$
\mathrm{AOR}=\frac{V_{\max } C}{K_{\mathrm{m}}+C},
$$

where AOR is the ammonia oxidation rate; $V_{\max }$ is the maximum ammonia oxidation rate in substrate-saturated conditions; $K_{\mathrm{m}}$ is the half-saturation constant corresponding to the concentration of substrate at which the rate is $50 \%$ of $V_{\max }$ and measures performance at low substrate concentrations. $C$ is the substrate concentration.

Temperature dependence of $V_{\max }$ should follow a left-skewed unimodal function of temperature. Within the optimum temperature in substrate-saturated conditions ( $\left.T_{\text {opt-sat }}\right), V_{\max }$ is expected to increase exponentially with temperature ${ }^{65}$, while the temperature dependence of $K_{\mathrm{m}}$ is inconsistent ${ }^{66-68}$. Several experimental studies in algae, plants and bacteria found positive correlations ${ }^{66}$ between $K_{\mathrm{m}}$ and temperature, while others found a negative relationship ${ }^{67}$ and still others found no evidence of temperature dependence ${ }^{68}$. According to theoretical study, $K_{\mathrm{m}}$ is expected to increase with temperature ${ }^{32}$. We assumed $K_{\mathrm{m}}$ to have a similar thermal response to $V_{\max }$, with the temperature dependence within the $T_{\text {opt-sat }}$ of both $V_{\max }$ and $K_{\mathrm{m}}$ following the Boltzmann-Arrhenius equation.

$$
\begin{gathered}
V_{\max }=V_{\max 0} e^{b_{\text {Vmax }} T}, \\
K_{\mathrm{m}}=K_{\mathrm{m} 0} e^{b_{\mathrm{Km}} T},
\end{gathered}
$$

where $V_{\max }$ and $K_{\mathrm{m}}$ are the maximum rate and the half-saturation constant, respectively, at temperature $(T) ; V_{\max 0}$ and $K_{\mathrm{m} 0}$ are the maximum rate and the half- saturation constant, respectively, at $0{ }^{\circ} \mathrm{C} ; b_{\mathrm{Vmax}}$ and $b_{\mathrm{Km}}$ are held constant and represent the temperature sensitivity coefficient.

The temperature sensitivities of $V_{\max }\left(\mathrm{Q} 10_{\mathrm{V} \max }\right)$ and $K_{\mathrm{m}}\left(\mathrm{Q} 10_{\mathrm{Km}}\right)$, which reflect the ratios of the change in $V_{\max }$ and $K_{\mathrm{m}}$ in response to a temperature increase of $10^{\circ} \mathrm{C}$, were calculated using Eqs. (5) and (6).

$$
\begin{gathered}
\mathrm{Q} 10_{\mathrm{Vmax}}=\mathrm{e}^{10 \mathrm{~b}_{\mathrm{V} \max }}, \\
\mathrm{Q} 10_{\mathrm{Km}}=\mathrm{e}^{10 \mathrm{~b}_{\mathrm{Km}}} .
\end{gathered}
$$

The DAMM model combines the Michaelis-Menten kinetic equation (Eq. 2) with the temperature dependence of $V_{\max }$ and $K_{\mathrm{m}}$ (Eqs. (3)-(6)) in order to describe how the substrate concentration and temperature affect the rate together (Eq. 7).

$$
\mathrm{AOR}=\frac{V_{\max 0} \times\left(\mathrm{Q}_{10} 0_{\mathrm{V} \max }\right)^{T / 10} \times C}{K_{\mathrm{m} 0} \times\left(\mathrm{Q} 10_{\mathrm{Km}}\right)^{T / 10}+C},
$$

where AOR is the ammonia oxidation rate at temperature $T ; V_{\max 0}$ and $K_{\mathrm{m} 0}$ are the $V_{\max }$ and $K_{\mathrm{m}}$ at $0{ }^{\circ} \mathrm{C}$, respectively; $\mathrm{Q} 10_{\mathrm{V} \max }$ and $\mathrm{Q} 10_{\mathrm{Km}}$ are the ratios of the change in $V_{\max }$ and $K_{\mathrm{m}}$, respectively, as a consequence of a $10^{\circ} \mathrm{C}$ increase in temperature (i.e. the temperature sensitivity coefficient); and $C$ is the substrate concentration.

The DAMM model has been shown to successfully predict observations of microbes in soil systems for a range of substrate concentrations and incubation temperatures in terms of laboratory enzyme assays of $\beta$-glucosidase and phenoloxidase $^{26}$.

In fact, since $T_{\mathrm{opt}}$ is defined as the temperature at which the rate reaches its maximum value at a fixed substrate concentration, the $T_{\mathrm{opt}}$ can be determined when the first-order derivative of the relationship between the rate and temperature is equal to 0 (the inflection point). Therefore,

$$
\frac{\partial_{V}}{\partial_{T}}=0 .
$$

When combined with Eqs. (7) and (8) this results in the $T_{\text {opt }}$ equation:

$$
T_{\text {opt }}=\frac{10 \times \log \left[\frac{C \times \log Q 10_{\mathrm{Vmax}}}{K_{\mathrm{mo}}\left(\log \mathrm{Q} 10_{\mathrm{Km}}-\log \mathrm{Q} 10_{\mathrm{Vmax}}\right)}\right]}{\log \mathrm{Q} 10_{\mathrm{Km}}} .
$$

Statistics and reproducibility. We analyzed our results with the collected data using the commercial software, the Grapher (version 15, Golden Software) and SPSS (IBM, version 19). The phenomenon of substrate-regulated thermal optimum for ammonia oxidation rate was reproduced at five independent stations.

Reporting summary. Further information on research design is available in the Nature Research Reporting Summary linked to this article.

\section{Data availability}

The datasets generated or analyzed during the current study are available in the Figshare repository, https://doi.org/10.6084/m9.figshare.12187794.v1

Received: 25 September 2019; Accepted: 24 June 2020;

Published online: 14 July 2020

\section{References}

1. Thamdrup, B. \& Dalsgaard, T. Production of $\mathrm{N}_{2}$ through anaerobic ammonium oxidation coupled to nitrate reduction in marine sediments. Appl. Environ. Microbiol. 68, 1312-1318 (2002).

2. Dalsgaard, T. \& Thamdrup, B. Factors controlling anaerobic ammonium oxidation with nitrite in marine sediments. Appl. Environ. Microbiol. 68 , 3802-3808 (2002).

3. Könneke, M. et al. Ammonia-oxidizing archaea use the most energy-efficient aerobic pathway for $\mathrm{CO}_{2}$ fixation. Proc. Natl Acad. Sci. USA 111, 8239-8244 (2014).

4. Yool, A., Martin, A. P., Fernández, C. \& Clark, D. R. The significance of nitrification for oceanic new production. Nature 447, 999-1002 (2007).

5. Santoro, A. E., Buchwald, C., McIlvin, M. R. \& Casciotti, K. L. Isotopic signature of $\mathrm{N}_{2} \mathrm{O}$ produced by marine ammonia-oxidizing archaea. Science 333, 1282-1285 (2011).

6. Gruber, N. \& Galloway, J. N. An Earth-system perspective of the global nitrogen cycle. Nature 451, 293-296 (2008)

7. Yang, S. \& Gruber, N. The anthropogenic perturbation of the marine nitrogen cycle by atmospheric deposition: Nitrogen cycle feedbacks and the ${ }^{15} \mathrm{~N}$ HaberBosch effect. Glob. Biogeochem. Cycles 30, 1418-1440 (2016). 
8. Beman, J. M. et al. Global declines in oceanic nitrification rates as a consequence of ocean acidification. Proc. Natl Acad. Sci. USA 108, 208-213 (2011).

9. Dutkiewicz, S. et al. Impact of ocean acidification on the structure of future phytoplankton communities. Nat. Clim. Change 5, 1002-1006 (2015).

10. Hutchins, D. A. \& Fu, F. Microorganisms and ocean global change. Nat. Microbiol. 2, 17058 (2017)

11. Greaver, T. et al. Key ecological responses to nitrogen are altered by climate change. Nat. Clim. Change 6, 836-843 (2016).

12. Walker, T. W. et al. Microbial temperature sensitivity and biomass change explain soil carbon loss with warming. Nat. Clim. Change 8, 885-889 (2018).

13. Hsiao, S. Y. et al. Nitrification and its oxygen consumption along the turbid Chang Jiang River plume. Biogeosciences 11, 2083-2098 (2014)

14. Pakulski, J. et al. Microbial metabolism and nutrient cycling in the Mississippi and Atchafalaya River plumes. Estuar. Coast. Shelf Sci. 50, 173-184 (2000).

15. Beman, J. M., Popp, B. N. \& Alford, S. E. Quantification of ammonia oxidation rates and ammonia-oxidizing archaea and bacteria at high resolution in the Gulf of California and eastern tropical North Pacific Ocean. Limnol. Oceanogr. 57, 711-726 (2012)

16. Peng, X. et al. Revisiting nitrification in the eastern tropical South Pacific: a focus on controls. J. Geophys. Res. -Oceans 121, 1667-1684 (2016).

17. Wan, X. S. et al. Ambient nitrate switches the ammonium consumption pathway in the euphotic ocean. Nat. Commun. 9, 915 (2018).

18. Qin, W. et al. Marine ammonia-oxidizing archaeal isolates display obligate mixotrophy and wide ecotypic variation. Proc. Natl Acad. Sci. USA 111, 12504-12509 (2014).

19. Baer, S. E., Connelly, T. L., Sipler, R. E., Yager, P. L. \& Bronk, D. A. Effect of temperature on rates of ammonium uptake and nitrification in the western coastal Arctic during winter, spring, and summer. Glob. Biogeochem. Cycles 28, 1455-1466 (2014).

20. Horak, R. E. A. et al. Ammonia oxidation kinetics and temperature sensitivity of a natural marine community dominated by Archaea. ISME J. 7, 2023-2033 (2013).

21. Horak, R. E. A. et al. Relative impacts of light, temperature, and reactive oxygen on thaumarchaeal ammonia oxidation in the North Pacific Ocean. Limnol. Oceanogr. 63, 741-757 (2017).

22. Zheng, Z. Z. et al. Effects of temperature and particles on nitrification in a eutrophic coastal bay in southern China. J. Geophys. Res-Biogeo. 122, 2325-2337 (2017).

23. Zheng, L., Cardenas, M. B. \& Wang, L. Temperature effects on nitrogen cycling and nitrate removal-production efficiency in bed form-induced hyporheic zones. J. Geophys. Res-Biogeo. 121, 1086-1103 (2016).

24. Polus, E., Flipo, N., De Fouquet, C. \& Poulin, M. Geostatistics for assessing the efficiency of a distributed physically-based water quality model: application to nitrate in the Seine River. Hydrol. Rrocess. 25, 217-233 (2011).

25. Davidson, E. A., Janssens, I. A. \& Luo, Y. On the variability of respiration in terrestrial ecosystems: moving beyond $\mathrm{Q}_{10}$. Glob. Change Biol. 12, 154-164 (2006).

26. Davidson, E. A., Samanta, S., Caramori, S. S. \& Savage, K. The Dual Arrhenius and Michaelis-Menten kinetics model for decomposition of soil organic matter at hourly to seasonal time scales. Glob. Change Biol. 18, 371-384 (2012).

27. Somero, G. N. Proteins and temperature. Annu. Rev. Physiol. 57, 43-68 (1995).

28. Somero, G. N. Adaptation of enzymes to temperature: searching for basic "strategies". Comp. Biochem. Phys. B. 139, 321-333 (2004)

29. Somero, G. N. Temperature. in Biochemical Adaptation: Response to Environmental Challenges, from Life's Origins to the Anthropocene (eds Somero, G. N., Lockwood, B. L. \& Tomanek, L.) (Incorporated Publishers, 2017).

30. Dong, Y. W., Liao, M. L., Meng, X. L. \& Somero, G. N. Structural flexibility and protein adaptation to temperature: Molecular dynamics analysis of malate dehydrogenases of marine molluscs. Proc. Natl Acad. Sci. USA 6, 1274-1279 (2018).

31. German, D. P., Marcelo, K. R. B., Stone, M. M. \& Allison, S. D. The Michaelis-Menten kinetics of soil extracellular enzymes in response to temperature: a cross-latitudinal study. Glob. Change Biol. 18, 1468-1479 (2012).

32. Thomas, M. K. et al. Temperature-nutrient interactions exacerbate sensitivity to warming in phytoplankton. Glob. Change Biol. 23, 3269-3280 (2017).

33. Gerard, V. A. The role of nitrogen nutrition in high-temperature tolerance of the kelp Laminaria saccharina (Chromophyta). J. Phycol. 33, 800-810 (1997).

34. Wiedenmann, J. et al. Nutrient enrichment can increase the susceptibility of reef corals to bleaching. Nat. Clim. Change 3, 160-164 (2013).

35. Hou, L. et al. Niche differentiation of ammonia and nitrite oxidizers along a salinity gradient from the Pearl River estuary to the South China Sea. Biogeosciences 15, 5169-5187 (2018).
36. Bouskill, N. J., Eveillard, D., Chien, D., Jayakumar, A. \& Ward, B. B. Environmental factors determining ammonia-oxidizing organism distribution and diversity in marine environments. Environ. Microbiol. 14, 714-729 (2012).

37. Ward, B., Talbot, M. \& Perry, M. Contributions of phytoplankton and nitrifying bacteria to ammonium and nitrite dynamics in coastal waters. Cont Shelf Res. 3, 383-398 (1984)

38. Kits, K. D. et al. Kinetic analysis of a complete nitrifier reveals an oligotrophic lifestyle. Nature 549, 269 (2017).

39. Nowka, B., Daims, H. \& Spieck, E. Comparison of oxidation kinetics of nitriteoxidizing bacteria: nitrite availability as a key factor in niche differentiation. Appl. Environ. Microbiol. 81, 745-753 (2015).

40. Schramm, A., de Beer, D., van den Heuvel, J. C., Ottengraf, S. \& Amann, R Microscale Distribution of populations and activities of Nitrosospira and Nitrospira spp. along a macroscale gradient in a nitrifying bioreactor: quantification by in situ hybridization and the use of microsensors. Appl. Environ. Microbiol. 65, 3690-3696 (1999).

41. Hayatsu, M. et al. An acid-tolerant ammonia-oxidizing $\gamma$-proteobacterium from soil. ISME J. 11, 1130-1141 (2017).

42. Martens-Habbena, W., Berube, P. M., Urakawa, H., de La Torre, J. R. \& Stahl, D. A. Ammonia oxidation kinetics determine niche separation of nitrifying Archaea and Bacteria. Nature 461, 976-979 (2009).

43. Groeneweg, J., Sellner, B. \& Tappe, W. Ammonia oxidation in nitrosomonas at $\mathrm{NH}_{3}$ concentrations near $\mathrm{k}_{\mathrm{m}}$ : Effects of $\mathrm{pH}$ and temperature. Water Res. 28, 2561-2566 (1994).

44. Koops, H. P. et al. in The prokaryotes (eds Dworkin, M., Falkow, S., Rosenberg, E., Schleifer, K. H. \& Stackebrandt, E.) (Springer, 2006).

45. Collins, M. et al. in The Physical Science Basis. Working Group I Contribution to the Fifth Assessment Report of the Intergovernmental Panel on Climate Change 2013 (eds Stocker, T. F. et al.) (Cambridge University, 2013).

46. Yang, Y. \& Hu, M. in Biogeochemical Research in Main Estuaries in China (eds Zhang, J.) (Chinese Ocean Press, 1996).

47. Yan, X., Cai, R. \& Bai, Y. Long-term change of the marine environment and plankton in the Xiamen Sea under the influence of climate change and human sewage. Toxicol. Environ. Chem. 98, 669-678 (2016).

48. $\mathrm{Du}, \mathrm{C}$. et al. Impact of the Kuroshio intrusion on the nutrient inventory in the upper northern South China Sea: insights from an isopycnal mixing model. Biogeosciences 10, 6419-6432 (2013).

49. Xing, X., Qiu, G., Boss, E. \& Wang, H. Temporal and vertical variations of particulate and dissolved optical properties in the South China Sea. J. Geophys. Res-Oceans 124, 3779-3795 (2019).

50. Ning, $X$. et al. Long term changes in the ecosystem in the northern South China Sea during 1976-2004. Biogeosciences 6, 2227-2243 (2009).

51. Duce, R. et al. Impacts of atmospheric anthropogenic nitrogen on the open ocean. Science 320, 893-897 (2008).

52. Schlesinger, W. H. On the fate of anthropogenic nitrogen. Proc. Natl Acad. Sci. USA 106, 203-208 (2009).

53. $\mathrm{Xu}, \mathrm{M}$. N. et al. Coupled effect of substrate and light on assimilation and oxidation of regenerated nitrogen in the euphotic ocean. Limnol. Oceanogr. 64, 1270-1283 (2019)

54. Hink, L., Gubry-Rangin, C., Nicol, G. W. \& Prosser, J. I. The consequences of niche and physiological differentiation of archaeal and bacterial ammonia oxidisers for nitrous oxide emissions. ISME J. 12, 1084-1093 (2018).

55. Bianchi, D., Weber, T. S., Kiko, R. \& Deutsch, C. Global niche of marine anaerobic metabolisms expanded by particle microenvironments. Nat. Geosci. 11, 263-268 (2018).

56. Zhu, Y. et al. A modified method for on-line determination of trace ammonium in seawater with a long-path liquid waveguide capillary cell and spectrophotometric detection. Mar. Chem. 162, 114-121 (2014).

57. Pai, S.-C., Tsau, Y.-J. \& Yang, T.-I. pH and buffering capacity problems involved in the determination of ammonia in saline water using the indophenol blue spectrophotometric method. Anal. Chim. Acta 434, 209-216 (2001).

58. Braman, R. S. \& Hendrix, S. A. Nanogram nitrite and nitrate determination in environmental and biological materials by vanadium (III) reduction with chemiluminescence detection. Anal. Chem. 61, 2715-2718 (1989).

59. Newell, S. E., Babbin, A. R., Jayakumar, A. \& Ward, B. B. Ammonia oxidation rates and nitrification in the Arabian Sea. Glob. Biogeochem. Cycles 25 GB4016 (2011).

60. Ward, B. in Methods in Enzymology (eds Klotz, M. G.) (Academic, 2011).

61. Shen, T., Stieglmeier, M., Dai, J., Urich, T. \& Schleper, C. Responses of the terrestrial ammonia-oxidizing archaeon ca. Nitrososphaera viennensis and the ammonia-oxidizing bacterium Nitrosospira multiformis to nitrification inhibitors. FEMS Microbiol. Lett. 344, 121-129 (2013).

62. Sigman, D. et al. A bacterial method for the nitrogen isotopic analysis of nitrate in seawater and freshwater. Anal. Chem. 73, 4145-4153 (2001). 
63. Casciotti, K., Sigman, D., Hastings, M. G., Böhlke, J. \& Hilkert, A. Measurement of the oxygen isotopic composition of nitrate in seawater and freshwater using the denitrifier method. Anal. Chem. 74, 4905-4912 (2002).

64. Ward, B. B. Light and substrate concentration relationships with marine ammonium assimilation and oxidation rates. Mar. Chem. 16, 301-316 (1985).

65. Dell, A. I., Pawar, S. \& Savage, V. M. Systematic variation in the temperature dependence of physiological and ecological traits. Proc. Natl Acad. Sci. USA 108, 10591-10596 (2011).

66. Carter, O. \& Lathwell, D. Effects of temperature on orthophosphate absorption by excised corn roots. Plant Physiol. 42, 1407-1412 (1967).

67. Reay, D. S., Nedwell, D. B., Priddle, J. \& Ellis-Evans, J. C. Temperature dependence of inorganic nitrogen uptake: reduced affinity for nitrate at suboptimal temperatures in both algae and bacteria. Appl. Environ. Microbiol. 65, 2577-2584 (1999).

68. Ahlgren, G. Temperature functions in biology and their application to algal growth constants. Oikos 49, 177-190 (1987).

\section{Acknowledgements}

We thank George N. Somero and Xianhui Wan for providing comments that greatly improved this paper. We greatly appreciate the help of Weijie Zhang and Li Liu with the onboard sampling in May, 2016, and the help from Jia Sun in November 2016. We also thank Tao Huang and Yifan Zhu for the on-board measurement of the nutrients. We are grateful for Xiuli Yan providing the nutrient data and Lili Han providing the gene data for the Jiulong River, and Siqi Wu providing seasonal temperature data of sea basin. We thank Zhixiong Huang and Moge Du for their help with the model practice. We are very grateful to Wenbin Zou and Li Tian for their strong technical support during the sample processing. This research was funded by the National Natural Science Foundation of China (NSFC no. $91851209,41721005,41561164019,41676060$, and 41806062), the Xiamen University President's fund (20720190110), and the MEL publication foundation (\#melpublication2019366)

\section{Author contributions}

Z.-Z.Z. and S.-J.K. designed the research. Z.-Z.Z., L.-W.Z., M.N.X., E.T., and W.D. performed the research. Z.-Z.Z., L.-W.Z., and S.-J.K. analyzed the data. Z.-Z.Z., L.-W.Z.,
M.N.X., E.T., D.A.H., W.D., Y.Z., D.S, M.D., and S.-J.K. contributed to the discussion of the results and wrote the paper.

\section{Competing interests}

The authors declare no competing interests.

\section{Additional information}

Supplementary information is available for this paper at https://doi.org/10.1038/s41467020-17366-3.

Correspondence and requests for materials should be addressed to S.-J.K.

Peer review information Nature Communications thanks the anonymous reviewers for their contributions to the peer review of this work. Peer review reports are available.

Reprints and permission information is available at http://www.nature.com/reprints

Publisher's note Springer Nature remains neutral with regard to jurisdictional claims in published maps and institutional affiliations.

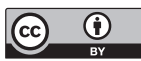

Open Access This article is licensed under a Creative Commons Attribution 4.0 International License, which permits use, sharing, adaptation, distribution and reproduction in any medium or format, as long as you give appropriate credit to the original author(s) and the source, provide a link to the Creative Commons license, and indicate if changes were made. The images or other third party material in this article are included in the article's Creative Commons license, unless indicated otherwise in a credit line to the material. If material is not included in the article's Creative Commons license and your intended use is not permitted by statutory regulation or exceeds the permitted use, you will need to obtain permission directly from the copyright holder. To view a copy of this license, visit http://creativecommons.org/ licenses/by/4.0/.

(C) The Author(s) 2020 